\title{
Electrocardiogram of secundum type atrial septal defect simulating endocardial cushion defect
}

\author{
King-Twok Tan, Atsuyoshi Takao, Akimasa Hashimoto, and Teiji Sato \\ From The Heart Institute of fapan, Tokyo Women's Medical College, ro Kawada-cho, Shinjuku-ku, Tokyo, \\ fapan
}

Three groups of patients are identified in the series of secundum atrial septal defect with left axis deviation in an analysis of 910 patients of secundum atrial septal defect with or without other accompanying anomalies: I) I2 patients with isolated ostium secundum defect; 2) 5 patients with associated prolapse of posterior leaflet of the mitral valve; 3) 4 patients with associated hypertrophic cardiomyopathy and/or single (left) coronary artery.

The findings of these $2 I$ patients with proved secundum atrial septal defect are analysed. The combination of such anomalies should be considered in the differential diagnosis of primum endocardial cushion defect from the electrocardiographic viewpoints.

The electrocardiogram is an important aid in differentiating between ostium secundum and ostium primum types of atrial septal defect. Toscano-Barbosa, Brandenburg, and Burchell (1956) were the first to stress that left axis deviation, counterclockwise rotation, and superior displacement of the QRS loop in the frontal plane were the characteristic electrocardiographic and vectorcardiographic findings in patients with ostium primum defect. Subsequently, many other reports (Blount, Balchum, and Gensini, 1956; Liebman and Nadas, 1960) also have confirmed that nearly 95 per cent of the patients with ostium primum defects reveal incomplete right bundle-branch block, right ventricular hypertrophy, left axis deviation, and counterclockwise rotation of the QRS loop.

There is still no agreement concerning the cause of these electrocardiographic phenomena in ostium primum. Some have ascribed the left ventricular hypertrophy to haemodynamically significant mitral regurgitation (Milnor and Bertrand, I957; Cooley and McNamara, 1958), while others have attributed the left axis deviation to an alteration in the exciting pathway (Toscano-Barbosa et al., 1956). However, recent opinion agrees that right bundle-branch block with left anterior hemiblock is the most acceptable cause of the left axis deviation (Lev, 1958; Feldt, DuShane, and Titus, 1970). Whether it is attributed to, I) abnormal development of the

Received I August 1974. left anterior branch (left anterior branch block) (Rosenbaum et al., 1970), or 2) early excitability of the left posterior branch (Durrer, Roos, and van Dam, I966), still remains to be resolved.

Details concerning the electro-anatomical abnormalities of primum defects have been stressed by many authors. However, there are few reports regarding those secundum defects with left axis deviation.

The purpose of this paper is to describe the findings in 21 patients with proven secundum atrial septal defect with left axis deviation, who were originally referred with a diagnosis of ostium primum atrial septal defect.

\section{Subjects and methods}

The present study is based on an analysis of 910 cases of secundum atrial septal defects with or without accompanying complications seen at the Heart Institute of Japan, Tokyo Women's Medical College, between May I965 and May 1973. Among these, 2 I cases (2.3\%) were found to have the electrocardiographic electrical axis in the frontal plane of $-10^{\circ}$ to $-160^{\circ}$. The diagnosis of secundum atrial septal defect was confirmed by right and left heart catheterization, angiocardiography, and operation.

Of 21 cases studied, I 3 were male and 8 female. The age of the patients ranged from 7 to 36 years. Surgical repair of the defects under direct vision was carried out in 17 patients. The electrocardiographic diagnosis of left axis deviation was evaluated upon the basis of the criteria of New York Heart Association. 
210 Tan, Takao, Hashimoto, and Sato

TABLE I Secundum atrial septal defect with left axis deviation without associated gross anomalies

\begin{tabular}{|c|c|c|c|c|c|c|c|c|c|}
\hline $\begin{array}{l}\text { Case } \\
\text { No. }\end{array}$ & Sex & $\begin{array}{l}\text { Age } \\
(y r)\end{array}$ & $\begin{array}{l}Q R S \\
\text { axis }\end{array}$ & $\begin{array}{l}P Q \\
\text { interval }\end{array}$ & $\begin{array}{l}Q R S \\
\left(V_{I}\right)\end{array}$ & $\begin{array}{l}\text { Frontal } \\
\text { plane vector }\end{array}$ & $\dot{Q} p / \dot{Q} s$ & $\begin{array}{l}\text { Size }(\mathrm{mm}) \text { and } \\
\text { location of } A S D \text { - } \\
\text { II }\end{array}$ & Diagnosis \\
\hline $\mathbf{I}$ & $\mathbf{M}$ & $2 \mathbf{I}$ & -30 & 0.12 & qrsR' & $\mathrm{CC}$ & 5.0 & $50 \times 30$ central & ASD-II \\
\hline 2 & $\mathbf{M}$ & II & -70 & 0.17 & $\mathbf{r s R}^{\prime} \mathbf{s}^{\prime}$ & CC & 2.9 & $30 \times 25$ central & , \\
\hline 3 & $\mathrm{~F}$ & 12 & - IIO & 0.14 & $\mathrm{qR}$ & CC & 3.9 & $30 \times 40$ central & , \\
\hline 4 & $\mathbf{M}$ & 26 & -10 & 0.12 & rSR' & CC & I.4 & $20 \times 60$ central & , \\
\hline 5 & $\mathbf{M}$ & 25 & -40 & 0.12 & $\mathbf{R s r}^{\prime} \mathbf{S}^{\prime}$ & CC & I. 8 & $30 \times 25$ central & , \\
\hline 6 & $\mathbf{M}$ & IO & -10 & 0.12 & rsr's' & $\mathrm{CC}$ & 2.0 & - & ", \\
\hline 7 & $\mathbf{F}$ & 7 & -30 & 0.20 & QrS & $\mathrm{CC}$ & I.4 & - & , \\
\hline 8 & $\mathbf{F}$ & 21 & -60 & 0.12 & $\mathbf{r s r}^{\prime}$ & $\mathrm{CC}$ & 1.9 & $30 \times 40$ central & " \\
\hline 9 & $\mathbf{F}$ & 34 & -30 & 0.12 & rsr's' & CC & 1.5 & - & 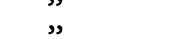 \\
\hline Io & $\mathbf{M}$ & II & -40 & 0.12 & $\mathbf{r s R}^{\prime} \mathbf{s}^{\prime}$ & $\mathrm{CC}$ & 1.6 & $25 \times 20$ central & $\begin{array}{l}\text { ASD-II } \\
\text { with mild } \\
\text { valvular PS }\end{array}$ \\
\hline I I & $\mathbf{M}$ & 17 & -90 & 0.18 & rsR' $\mathbf{S}^{\prime}$ & $\mathrm{CC}$ & 2.0 & - & \\
\hline 12 & $\mathbf{M}$ & 14 & -60 & 0.12 & $\mathbf{r s R}^{\prime} \mathbf{S}^{\prime}$ & $\mathrm{CC}$ & 2.6 & $12 \times 30$ central & $\begin{array}{l}\text { ASD-II with } \\
\text { mild MR }\end{array}$ \\
\hline
\end{tabular}

CC, counterclockwise; $\dot{\mathrm{p}} / \mathbf{Q} \mathrm{s}$, pulmonary to systemic flow ratio.

TABLE 2 Secundum atrial septal defect with left axis deviation and associated prolapse of posterior leaflet of mitral valve

\begin{tabular}{|c|c|c|c|c|c|c|c|c|c|c|}
\hline $\begin{array}{l}\text { Case } \\
\text { No. }\end{array}$ & Sex & $\begin{array}{l}\text { Age } \\
(y r)\end{array}$ & $\begin{array}{l}\text { QRS } \\
\text { axis }\end{array}$ & $\begin{array}{l}P Q \\
\text { interval }\end{array}$ & $\begin{array}{l}Q R S \\
(V I)\end{array}$ & $R V H$ & $\begin{array}{l}\text { Frontal } \\
\text { plane } \\
\text { vector }\end{array}$ & $\dot{Q} p / \dot{Q} s$ & $\begin{array}{l}\text { Size }(\mathrm{mm}) \text { and } \\
\text { location of } A S D \text { - } \\
\text { II }\end{array}$ & Diagnosis \\
\hline 13 & $\mathbf{M}$ & II & -60 & 0.14 & $\mathbf{r s} \mathbf{R}^{\prime}$ & - & CC & 4.5 & $50 \times 30$ central & $\begin{array}{l}\text { ASD II, pro- } \\
\text { lapse of pos- } \\
\text { terior leaflet } \\
\text { mitral valve }\end{array}$ \\
\hline 14 & $\mathbf{F}$ & 12 & -10 & 0.12 & $\mathbf{r s} \mathbf{R}^{\prime}$ & + & $\mathrm{CC}$ & 4.0 & I5 $\times 30$ central & , \\
\hline 15 & $\mathbf{F}$ & 14 & -30 & 0.16 & $\mathbf{r S r}^{\prime}$ & - & CC & 2.5 & $60 \times 30$ central & 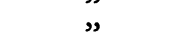 \\
\hline 16 & $\mathbf{M}$ & 9 & -10 & 0.12 & $\mathbf{r S R}^{\prime}$ & - & $\mathrm{CC}$ & 2.8 & $30 \times 50$ central & 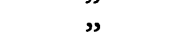 \\
\hline 17 & $\mathbf{F}$ & II & -50 & 0.16 & $\mathbf{r s R ^ { \prime } \mathbf { S } ^ { \prime }}$ & - & CC & 4.0 & $30 \times 40$ central & 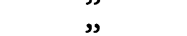 \\
\hline
\end{tabular}

CC, counterclockwise; $\dot{\mathrm{Q}} / \dot{\mathrm{Q}} \mathrm{s}$, pulmonary to systemic flow ratio.

TABLE 3 Secundum atrial septal defect with left axis deviation and associated hypertrophic cardiomyopathy

\begin{tabular}{|c|c|c|c|c|c|c|c|c|c|c|c|}
\hline $\begin{array}{l}\text { Case } \\
\text { No. }\end{array}$ & Sex & $\begin{array}{l}\text { Age } \\
(y r)\end{array}$ & $\underset{\text { axis }}{Q R S}$ & $\begin{array}{l}P Q \\
\text { interval }\end{array}$ & $\begin{array}{l}Q R S \\
V_{I}\end{array}$ & $V_{3}$ & V6 & $\begin{array}{l}\text { Frontal } \\
\text { plane } \\
\text { vector }\end{array}$ & $\dot{Q} p / \dot{Q} s$ & $\begin{array}{l}\text { Pressure } \\
\text { (mmHg) } \\
P A\end{array}$ & $R V$ \\
\hline 18 & $\mathbf{M}$ & 19 & -160 & 0.24 & $\mathrm{qR}$ & rS & RS & $\mathrm{CC}$ & 1.9 & $\begin{array}{l}21 / 9 \\
(4) \\
2.8 / 1.2 \\
(0.5)\end{array}$ & $\begin{array}{c}46 / 7 \\
(14) \\
6.1 / 0.9 \\
(1.9)\end{array}$ \\
\hline 19 & $\mathbf{M}$ & 15 & -90 & 0.16 & $\mathrm{rS}$ & QS & rS & $\mathrm{CC}$ & 1.5 & $\begin{array}{l}40 / 20 \\
(25) \\
5.3 / 2.7 \\
(3.3)\end{array}$ & $\begin{array}{c}43 / 0 \\
(14) \\
5.7 / 0 \\
(I .9)\end{array}$ \\
\hline 20 & $\mathbf{M}$ & 12 & -130 & 0.16 & $r s R^{\prime} S^{\prime}$ & rS & rs & $\mathrm{CC}$ & 1.4 & $\begin{array}{l}20 / 10 \\
(14) \\
2.7 / 1.3 \\
(1.9)\end{array}$ & $\frac{78 / 0}{10.4 / 0}$ \\
\hline 21 & $\mathbf{F}$ & 36 & -40 & 0.16 & $\mathbf{r S R ^ { \prime }}$ & $\mathbf{r s R}^{\prime}$ & qRs & $\mathrm{CC}$ & 5.0 & $\begin{array}{c}44 / 12 \\
(23) \\
5.8 / 1.6 \\
(I .7)\end{array}$ & $\begin{array}{c}48 / 8 \\
(19) \\
6.4 / 1.1 \\
(2.5)\end{array}$ \\
\hline
\end{tabular}

CC, counterclockwise. $\dot{\mathrm{Q}} / \dot{\mathrm{Q}} \mathrm{s}$, pulmonary to systemic flow ratio. PA, pulmonary artery. RV, right ventricle. PLSVC, persistent left superior vena cava. Italicised figures are pressures in $\mathrm{kPa}$. 


\section{Results}

Three groups of patients are identified in the series of secundum atrial septal defect with left axis deviation (Tables I, 2, 3): I) without associated gross anomalies; 2) with associated prolapse of the posterior leaflet of the mitral valve (Fig. I); 3) with associated hypertrophic cardiomyopathy and/or single coronary artery (see Fig. 4 and 5).

\section{Without associated gross anomalies}

Twelve patients are identified in this group, including one with associated mild pulmonary valvular stenosis and one with mild mitral regurgitation. The mean QRS axis was $-10^{\circ}$ to $-110^{\circ}$, and the direction of inscription of the QRS loop in the frontal plane was counterclockwise in all instances. There was only one patient with $P Q$ prolongation of $0.2 \mathrm{~s}$. The diagnosis of secundum atrial septal defect was confirmed by right and left heart catheterization and left ventriculography, and in 8 of these patients the diagnosis was confirmed at surgery. The average ratio of pulmonary to systemic flow at atrial level was 2.3 with a range of 1.4 to 5.0.

\section{With associated prolapse of posterior leaflet of mitral valve}

Among 8 patients who had secundum septal defect with associated prolapse of the posterior leaflet of the mitral valve (Fig. I), 5 were found to have counterclockwise direction of the QRS loop in the frontal plane with the mean $Q R S$ axis of $-10^{\circ}$ to $-60^{\circ}$. The PQ interval was not prolonged; and

and/or single coronary artery

Size ( $\mathrm{mm})$ and location of Diagnosis ASD-II

$40 \times 20$ central

$20 \times$ IO central

$30 \times 20$ central

$50 \times 30$ central
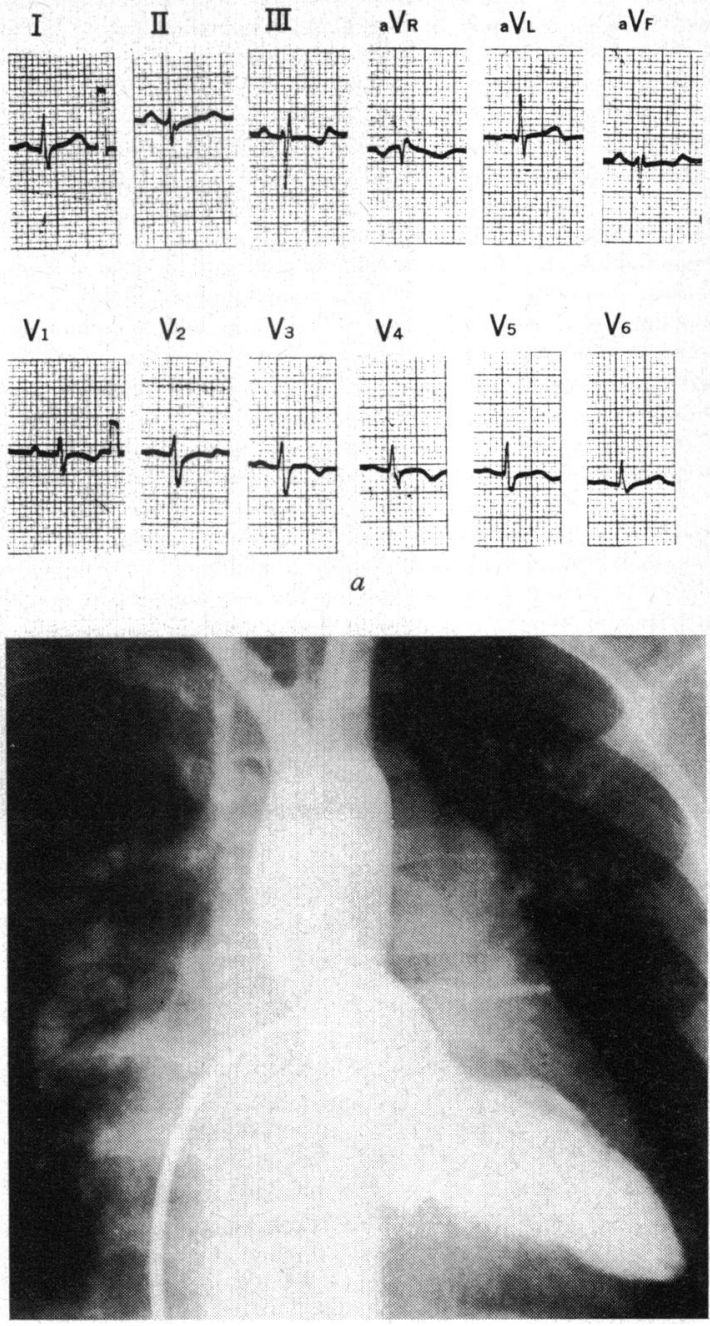

b

FIG. I a) Electrocardiogram of Case 17, showing left axis deviation. b) Left ventricular angiocardiogram (anteroposterior view) showing billowing of the posterior leaflet of the mitral valve into the left atrium.

mild mitral regurg., hypertrophy of ventricular septum

Noonan syndrome, ASD-II, pulm. valve. sten., PLSVC, hypertrophy of ventricular septum, single coronary artery

ASD-II, single coronary artery 


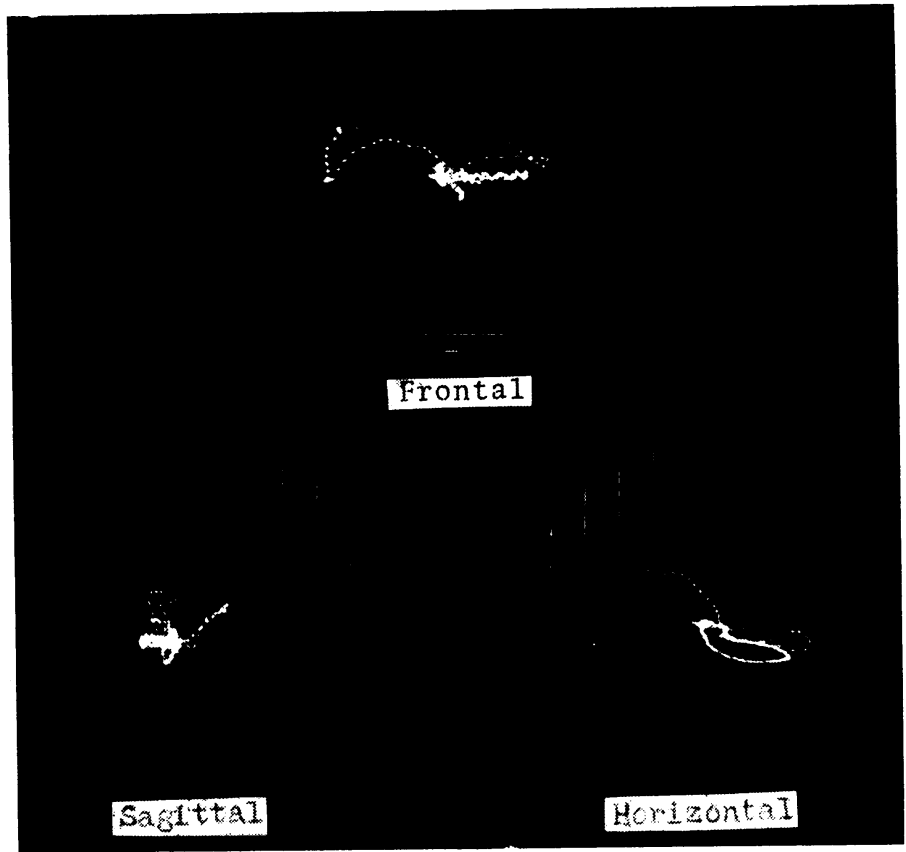

$a$
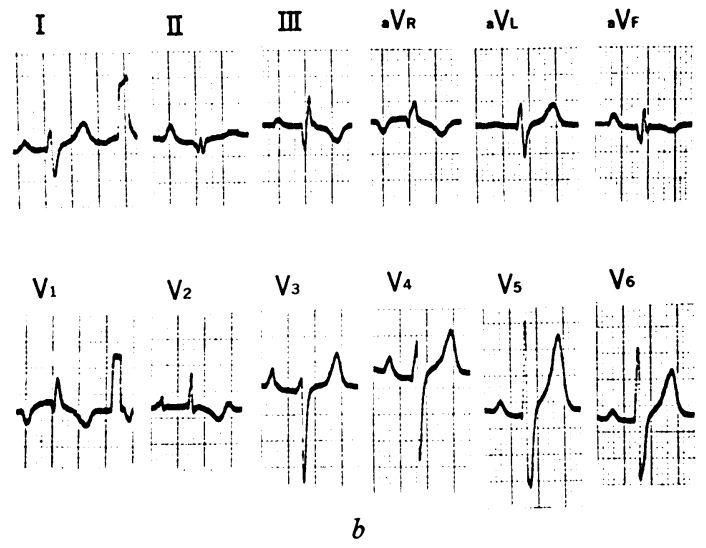

FIG. 2 a) Vectorcardiogram from Case I8, showing right ventricular hypertrophy and counterclockwise direction of the $Q R S$ loop in the frontal plane with the mean $Q R S$ axis of about $-160^{\circ}$. b) Electrocardiogram of Case 18, showing left axis deviation and right ventricular hypertrophy. c) Left ventricular angiocardiogram showing septal bulging into the cavity and massive hypertrophy of the left ventricular muscle.

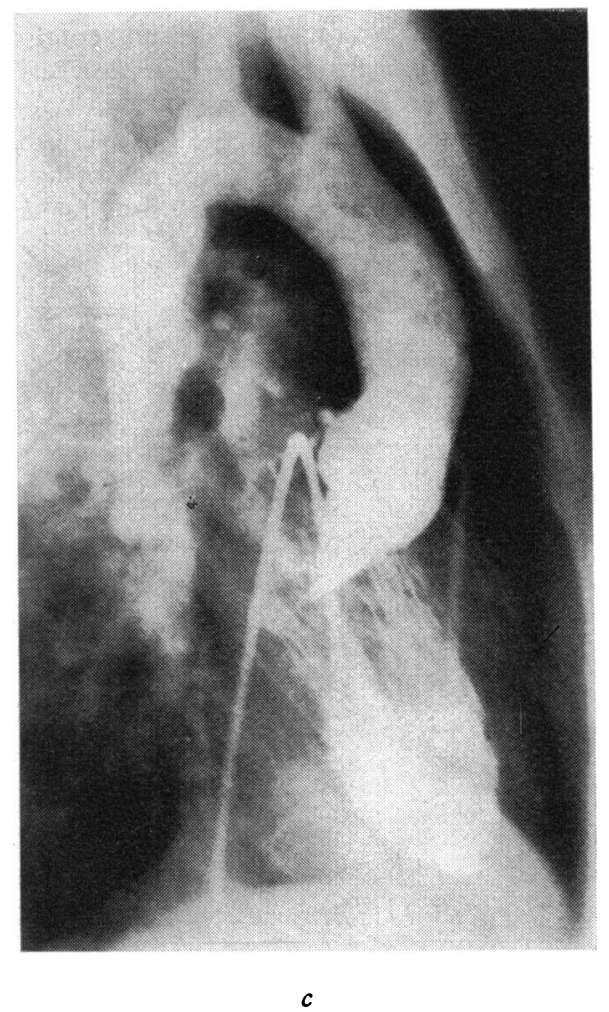



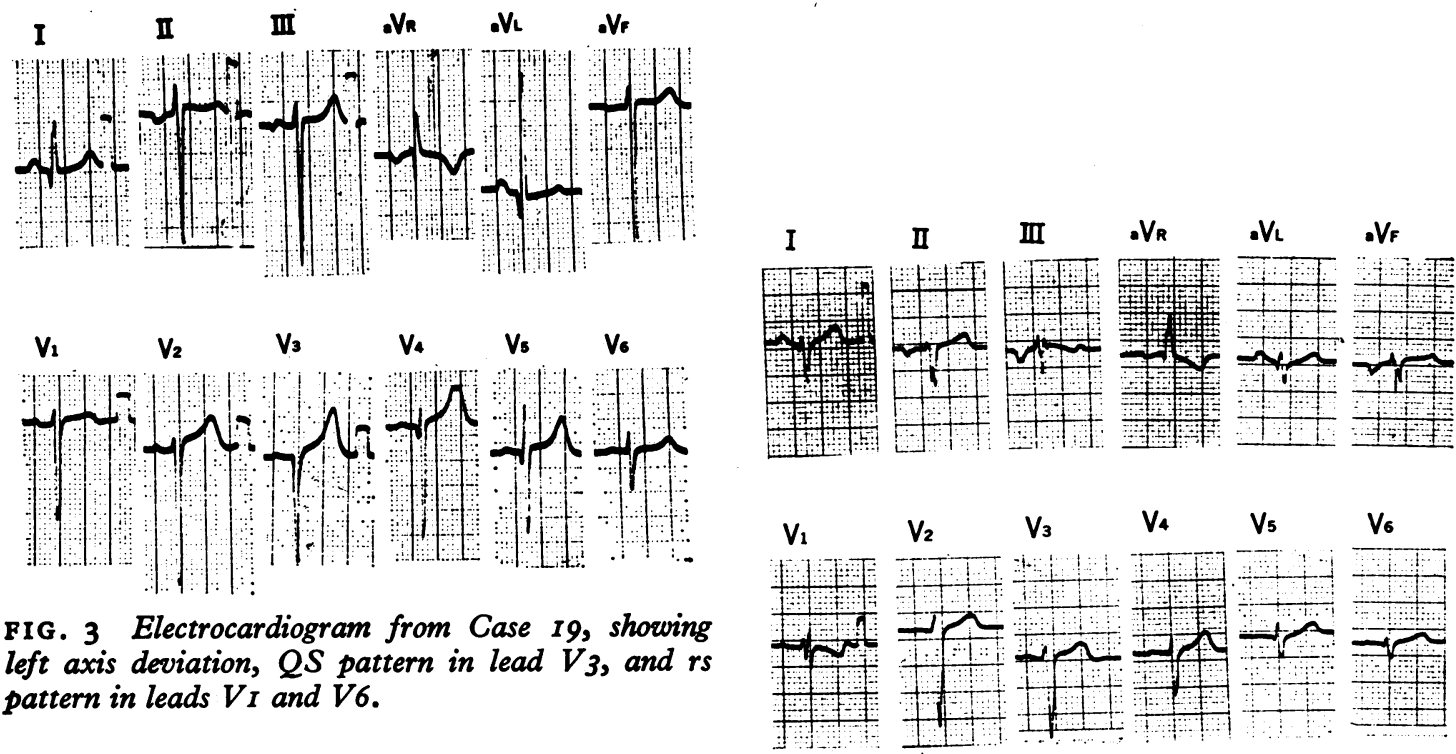

FIG. 3 Electrocardiogram from Case 19, showing left axis deviation, $Q S$ pattern in lead $V_{3}$, and $r$ pattern in leads VI and V6.

FIG. 4 a) Electrocardiogram from Case 20, showing right superior axis, right bundle-branch block, and rs pattern in V6. b) and c) Selective angiocardiograms from Case 20; b) right ventricular angiocardiogram showing septal bulging into the cavity and massive hypertrophy of the right ventricular muscle; c) left ventricular angiocardiogram showing single left coronary artery; right coronary artery is absent. 

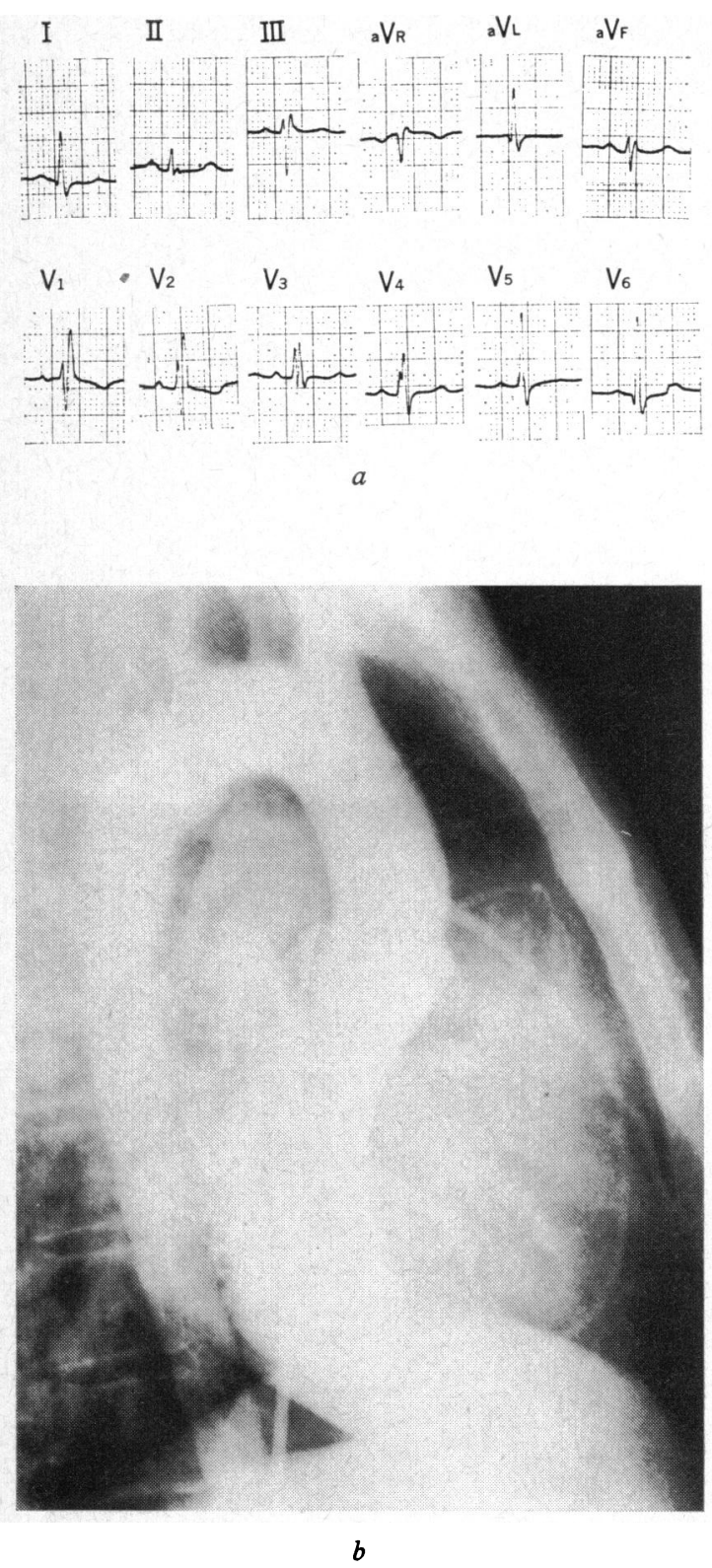

FIG. 5 a) Electrocardiogram from Case 21 , showing left axis deviation and right bundle-branch block. b) Left ventricular angiocardiogram showing high origin of single (left) coronary artery. Right coronary artery was emerging from the proximal part of the left single coronary artery. patients, all of whom had a large centrally positioned secundum defect.

With associated hypertrophic cardiomyopathy and/or single coronary artery

Four patients belonged to this group (Table 3). These showed features of hypertrophic ventricular septum (Fig. 2); Noonan's syndrome with hypertrophic ventricular septum and mild mitral regurgitation (Fig. 3); Noonan's syndrome with hypertrophic ventricular septum, pulmonary valvular stenosis, persistent left superior vena cava, and single coronary artery (Fig. 4); and single coronary artery (Fig. 5), respectively. The mean QRS axis was $-40^{\circ}$ to $-160^{\circ}$ and the direction of inscription of the QRS loop in the frontal plane was counterclockwise in all instances. The PQ interval was prolonged only in one patient. In Case I9, VI was rS, $\mathrm{V}_{3} \mathrm{QS}$, and $\mathrm{V} 6 \mathrm{rS}$; this gave rise to a suspicion of cardiomyopathy.

The presence of secundum atrial septal defect and associated diseases was confirmed by catheterization, angiocardiography, and operative findings. The average ratio of pulmonary to systemic flow at atrial level was 2.5. Surgical repair was confined to the closure of the secundum defects; the hypertrophic cardiomyopathy and single coronary artery were not treated.

\section{Discussion}

Opinions differ as to the degree of QRS axis in left axis deviation. According to the New York Heart Association (1964), the criterion is $-29^{\circ}$ to $-90^{\circ}$. However, other reports give $-15^{\circ}$ to $-90^{\circ}$ (Grant, 1956) and $-30^{\circ}$ to $-90^{\circ}$ (Pryor and Blount, 1966).

The cause of electrocardiographic left axis deviation is still unknown. Because of its characteristic occurrence in patients with primum defects, some (Milnor and Bertrand, 1957; Cooley and McNamara, 1958; Campbell and Missen, 1957) favoured the view that the left axis deviation was related to left ventricular hypertrophy caused by significant mitral regurgitation. If the left axis deviation and a counterclockwise rotation of the frontal plane QRS loop were to disappear after surgery, it would suggest strongly that these changes were caused by left ventricular hypertrophy rather than by congenital aberration of the left bundle-branch. But persisting left axis deviation after successful surgery in followup electrocardiographic and vectorcardiographic studies of patients with ostium primum made this view untenable (Burchell, DuShane, and Brandenberg, 1960; Lee and Sherlis, 1962). Thus, the concept of alteration of the conduction pathways has been favoured in recent studies. 
Durrer et al. (1966) thought that early excitation of the postero-basal region of the left ventricle was the main cause of left axis deviation. On the other hand, Rosenbaum et al. (1970) insisted that abnormal development of the left anterior branch or disruption of the left anterior branch because of a primum defect were the important factors. The genesis of this electrocardiogram has not been established conclusively.

In the present study, 2I patients who were diagnosed as having ostium secundum defects had left axis deviation and counterclockwise rotation of the QRS loop in the frontal plane. There were only two instances complicated by mild mitral regurgitation. Of the 5 patients with associated prolapse of the posterior leaflet of mitral valve, no case was found to have mitral regurgitation.

A case of secundum atrial septal defect with left axis deviation and associated hypertrophic cardiomyopathy has been described by Somerville and McDonald (1968). We have also found 3 patients with the same characteristics in the series. One had a strange face and build, with some of the features seen in the mosaic forms of Turner's syndrome, as described by Somerville and McDonald; and 2 had Noonan's syndrome.

Single (left) coronary artery also was found in 2 of the series: I was a case of Noonan's syndrome.

The occurrence of left axis deviation of the frontal plane QRS loop in secundum type atrial septal defect associated with the above-mentioned anomalies is interesting. Whether the associations are significant in regard to the aetiology of left axis deviation is unknown. Such a combination of anomalies should be considered in the differential diagnosis of endocardial cushion defect from the electrocardiographic standpoint.

\section{References}

Blount, S. G., Balchum, O. J., and Gensini, G. (1956). The persistent ostium primum atrial septal defect. Circulation, 13, 499.

Burchell, H. B., DuShane, J. W., and Brandenburg, R. O. (1960). The electrocardiogram of patients with atrioventricular cushion defects (defects of the atrioventricular canal). American fournal of Cardiology, 6, 575.
Campbell, M., and Missen, G. A. K. (1957). Endocardial cushion defects. Common atrioventricular canal and ostium primum. British Heart fournal, 19, 403.

Cooley, D. A., and McNamara, D. G. (1958). Ostium primum and atrioventricularis communis defects. Clinical manifestations and surgical treatment. Progress in Cardiovascular Diseases, $\mathbf{1}, 89$.

Durrer, D., Roos, J. P., and van Dam, R. Th. (1966). The genesis of the electrocardiogram of patients with ostium primum defects (ventral atrial septal defects). American Heart fournal, 71, 642 .

Feldt, R. H., DuShane, J. W., and Titus, J. L. (1970). The atrioventricular conduction system in persistent common atrioventricular canal defect. Correlations with electrocardiogram. Circulation, 42, 437.

Grant, R. P. (1956). Left axis deviation. An electrocardiographic-pathologic correlation study. Circulation, 14, 233.

Lee, Y. C., and Sherlis, L. (1962). Atrial septal defect. Electrocardiographic, vectorcardiographic, and catheterization data. Circulation, 25, ro24.

Lev, M. (1958). The architecture of the conduction system in congenital heart disease. I. Common atrioventricular orifice. Archives of Pathology, 65, 174.

Liebman, J., and Nadas, A. S. (1960). The vectorcardiogram in the differential diagnosis of atrial septal defect in children. Circulation, 22, 956.

Milnor, W. R., and Bertrand, C. A. (1957). The electrocardiogram in atrial septal defect. A study of twentyfour cases with observations on the RSR'-VI pattern. American fournal of Medicine, 22, 223.

New York Heart Association, Criteria Committee (1964). Diseases of the Heart and Blood Vessels. Nomenclature and Criteria for Diagnosis, 6th ed. Little, Brown, Boston.

Pryor, R., and Blount, S. G. (1966). The clinical significance of true left axis deviation. Left intraventricular blocks. American Heart fournal, 72, 391.

Rosenbaum, M. B., Corrado, G., Oliveri, R., Castellanos, A., Jr., and Elizari, M. V. (1970). Right bundle-branch block with left anterior hemiblock surgically induced in tetralogy of Fallot. Relation to the mechanism of electrocardiographic changes in endocardial cushion defect. American fournal of Cardiology, 26, 12.

Somerville, J., and McDonald, L. (1968). Congenital anomalies in the heart with hypertrophic cardiomyopathy. British Heart fournal, 30, 713.

Toscano-Barbosa, E., Brandenburg, R. O., and Burchell, H. B. (1956). Electrocardiographic studies of cases with intracardiac malformations of the atrioventricular canal. Proceedings of the Staff Meetings of the Mayo Clinic, 31, 513.

Requests for reprints to Dr. Atsuyoshi Takao, The Heart Institute, Japan, Tokyo Women's Medical College, Io Kawada-cho, Shinjuku-ku, Tokyo I62, Japan. 